\title{
Clinical and Laboratorial Features That May Differentiate 46,XY DSD due to Partial Androgen Insensitivity and $5 \alpha$-Reductase Type 2 Deficiency
}

\author{
Nélio Neves Veiga-Junior, ${ }^{1,2}$ Pedro Augusto Rodrigues Medaets, ${ }^{1,2}$ \\ Reginaldo José Petroli, ${ }^{1,3}$ Flávia Leme Calais, ${ }^{1,3}$ Maricilda Palandi de Mello, ${ }^{1,3}$ \\ Carla Cristina Telles de Sousa Castro, ${ }^{1,2}$ Guilherme Guaragna-Filho, ${ }^{1,2}$ \\ Letícia Espósito Sewaybricker, ${ }^{1,2}$ Antonia Paula Marques-de-Faria,, 4 \\ Andréa Trevas Maciel-Guerra, ${ }^{1,4}$ and Gil Guerra-Juniorr, ${ }^{1,2}$ \\ ${ }^{1}$ Interdisciplinary Group for the Study of Sex Determination and Differentiation (GIEDDS), \\ Faculty of Medical Sciences (FCM),State University of Campinas (UNICAMP), 13083-970 Campinas, SP, Brazil \\ ${ }^{2}$ Pediatric Endocrinology Unit, Department of Pediatrics, Faculty of Medical Sciences (FCM), \\ State University of Campinas (UNICAMP), 13083-970 Campinas, SP, Brazil \\ ${ }^{3}$ Center of Molecular Biology and Genetic Engineering (CBMEG), State University of Campinas (UNICAMP), \\ 13083-875 Campinas, SP, Brazil \\ ${ }^{4}$ Department of Medical Genetics, Faculty of Medical Sciences (FCM), State University of Campinas (UNICAMP), \\ 13083-970 Campinas, SP, Brazil
}

Correspondence should be addressed to Maricilda Palandi de Mello, mmello@unicamp.br

Received 31 July 2011; Revised 7 October 2011; Accepted 3 November 2011

Academic Editor: Olaf Hiort

Copyright (C) 2012 Nélio Neves Veiga-Junior et al. This is an open access article distributed under the Creative Commons Attribution License, which permits unrestricted use, distribution, and reproduction in any medium, provided the original work is properly cited.

\begin{abstract}
The aim of this study was to search for clinical and laboratorial data in 46,XY patients with ambiguous genitalia (AG) and normal testosterone (T) synthesis that could help to distinguish partial androgen insensitivity syndrome (PAIS) from $5 \alpha$-reductase type 2 deficiency ( $5 \alpha$-RD2) and from cases without molecular defects in the $A R$ and SRD5A2 genes. Fifty-eight patients (51 families) were included. Age at first evaluation, weight and height at birth, consanguinity, familial recurrence, severity of AG, penile length, LH, FSH, T, dihydrotestosterone (DHT), $\triangle 4$-androstenedione $(\triangle 4)$, and T/DHT and T/ $\triangle 4$ ratios were evaluated. The $A R$ and $S R D 5 A 2$ genes were sequenced in all cases. There were 9 cases ( 7 families) of $5 \alpha$-RD2, 10 cases ( 5 families) of PAIS, and 39 patients had normal molecular analysis of SRD5A2 and AR genes. Age at first evaluation, birth weight and height, and T/DHT ratio were lower in the undetermined group, while penile length was higher in this group. Consanguinity was more frequent and severity of AG was higher in $5 \alpha$-RD2 patients. Familial recurrence was more frequent in PAIS patients. Birth weight and height, consanguinity, familial recurrence, severity of AG, penile length, and T/DHT ratio may help the investigation of 46,XY patients with AG and normal T synthesis.
\end{abstract}

\section{Introduction}

The disorders of sex development (DSD) with sex ambiguity and 46,XY karyotype can be classified in three main groups: (1) disorders of gonadal development (ovotesticular DSD and partial gonadal dysgenesis), (2) disorders of testosterone synthesis (testosterone biosynthesis defects like steroidogenic acute regulatory protein (STAR) deficiency, side-chain cleavage (CYP11A1) deficiency, $3 \beta$-hydroxysteroid dehydrogenase type II (HSD3B2) deficiency, 17 $\alpha$-hydroxylase/17,20-lyase (CYP17A1) deficiency, 17 $\beta$-hydroxysteroid dehydrogenase III (HSD17B3) deficiency, P450 oxidoreductase (POR) defect; cytochrome b5 (CYB5) defect, and defects in luteinizing hormone action (LHCGR defect)), and (3) disorders 
of testosterone action [partial (PAIS) androgen insensitivity syndromes] or metabolization ( $5 \alpha$-reductase type 2 deficiency) [1].

The main diagnosis for patients with ambiguous genitalia and 46,XY karyotype (46,XY DSD) with normal testosterone secretion and normal Müllerian duct regression is PAIS or $5 \alpha$-reductase type 2 deficiency. Before puberty, the phenotypes of $46, \mathrm{XY}$ DSD due to androgen insensitivity syndromes or $5 \alpha$-reductase type 2 deficiency are, in general, indistinguishable, particularly when there is no parental consanguinity ( $5 \alpha$-reductase type 2 deficiency is an autosomal recessive disorder) or family history consistent with X-linked inheritance (androgen insensitivity syndromes) [2-5].

Despite the multiple genetic causes of 46,XY DSD, around $30-40 \%$ of cases remain without diagnosis [6]. Currently, there is a frequent, nongenetic variant of $46, \mathrm{XY}$ DSD characterized by reduced prenatal growth and lack of clear evidence for any associated malformation or steroidogenic defect. Additionally, other studies in undetermined $46, \mathrm{XY}$ DSD report that around 30\% of cases are associated with low birth weight, indicating that adverse events in early pregnancy are frequent causes of congenital nongenetic $46, \mathrm{XY}$ DSD $[7,8]$.

For that reason, the aim of this study was to search for clinical and laboratorial features of 46,XY patients with ambiguous genitalia and normal testosterone synthesis that could help to distinguish PAIS from $5 \alpha$-reductase type 2 deficiency and from cases without molecular defects in the $A R$ and SRD5A2 genes.

\section{Methods}

In the last 10 years (from January 2001 to December 2010), the Interdisciplinary Group for the Study of Sex Determination and Differentiation (GIEDDS) from the Clinical Hospital of the Faculty of Medical Sciences of State University of Campinas (UNICAMP), Brazil evaluated 58 patients (51 families) with ambiguous genitalia having a 46,XY karyotype and normal testosterone secretion after hCG stimulation. This study was performed according to the Helsinki declaration and was approved by the Ethical Research Committee of Faculty of Medical Sciences of UNICAMP. Informed consent was obtained from all participants and from parents of participants under 18 years of age.

All patients included in this study were born at term. They underwent laparoscopy during genitoplasty, orchidopexy, and/or gonadectomy, and no Müllerian structures were found.

Data were obtained regarding age at first evaluation, weight and length at birth, history of parental consanguinity, family history of ambiguous genitalia or infertility, severity of the ambiguous genitalia (according to Sinnecker et al. classification [9] and Ahmed et al. external masculinization score (EMS) [10]), penile length (in z score according to Gabrich et al. [11]), levels of LH, FSH, total testosterone (T), dihydrotestosterone (DHT), T/DHT ratio, $\Delta 4$-androstenedione, and $\mathrm{T} / \Delta 4$ ratio. $\mathrm{LH}, \mathrm{FSH}$, and $\Delta 4$-androstenedione were evaluated by chemiluminescence immunoassay, $\mathrm{T}$ and DHT by radioimmunoassay. $\mathrm{T}$ was evaluated at basal levels in all patients, and in all prepubertal patients, a stimulation test was carried out by giving 1,500 IU of hCG by intramuscular injections for three consecutive days on an outpatient basis. Venous samples were taken before the test and approximately 24 hours after the third hCG injection and $\mathrm{T}$ was considered normal if above than $1,5 \mathrm{ng} / \mathrm{mL}$ [11]. In patients with complete puberty (Tanner 4 or 5 ), a hCG-stimulation test was carried out only if $\mathrm{T}$ was below $9 \mathrm{ng} / \mathrm{mL}$.

Molecular analyses of SRD5A2 and $A R$ genes were performed for all patients. The eight exons of $A R$ gene and the five exons of $S R D 5 A 2$ were amplified from genomic DNA using the polymerase chain reaction (PCR) followed by sequencing the fragments with Big Dye Terminator Cycle Sequencing Kit V3.1 Ready Reaction (ABI PRISM/PE Biosystems). The sequences were compared with the normal sequence of each gene (ENSEMBL: ENSG00000049319 and ENSG00000169083) using CLC Sequence Viewer v.6.2 (free software).

According to clinical and molecular data, the cases were classified in three groups of diagnosis: (1) $5 \alpha$-reductase type 2 deficiency, (2) PAIS, and (3) undetermined (without molecular defects in either AR or SRD5A2 gene).

Data were processed in the SPSS program for Windows, version 16.0, and descriptive analyses for continuous variables were made by calculating range, means and standard deviation. The data were compared among the three groups using Chi-square test or Fisher's exact test for categorical variables and Kruskal-Wallis test for continuous variables. For all analyses, a significance level of $P<0.05$ was adopted.

\section{Results}

Data from all 58 patients are shown in Tables 1, 2, and 3. Nine patients (7 families) showed homozygous or compound heterozygous mutations in SRD5A2 gene (Table 1), confirming the diagnosis of $5 \alpha$-reductase type 2 deficiency in these patients. Only c.278delG mutation (patient 4: Table 1) was not yet described in the literature. Ten patients (5 families) showed hemizygous mutation in $A R$ gene, confirming the diagnosis of PAIS (Table 2). The remaining 39 cases showed normal molecular analysis of SRD $5 A 2$ and $A R$ genes (Table 3).

Table 4 shows the frequency of parental consanguinity, familial recurrence, and severity of ambiguous genitalia in the three groups. The frequency of parental consanguinity was significantly higher in patients with $5 \alpha$-reductase type 2 deficiency $\left(\chi_{(2)}^{2}=19.86, P=0.00005\right)$, whereas familial recurrence was significantly more frequent in the groups of PAIS $\left(\chi_{(2)}^{2}=8.14, P=0.02\right)$. The severity of ambiguous genitalia according to Sinnecker et al. [9] classification $\left(\chi_{(2)}^{2}=\right.$ $15.49, P=0.0004)$ and according to Ahmed et al. [10] score $\left(\chi_{(2)}^{2}=20.89, P=0.00003\right)$ was significantly higher in the group of $5 \alpha$-reductase type 2 deficiency and PAIS in relation to undetermined cases. Analyzing only the patients with $5 \alpha$ reductase type 2 deficiency and PAIS, the Sinnecker et al. [9] classification was significantly higher in PAIS $\left(\chi_{(2)}^{2}=6.41\right.$, $P=0.04$ ), while the Ahmed et al. [10] score did not show significant differences between these two groups of patients 
Table 1: Data from 9 patients (7 families) of $5 \alpha$-reductase type 2 deficiency.

\begin{tabular}{lcccccccccc}
\hline Case & Age $1(\mathrm{yr})$ & Birth weight $(\mathrm{g})$ & Birth length $(\mathrm{cm})$ & Penile $(\mathrm{z})$ & Genital $^{1}$ & Genital $^{2}$ & T $(\mathrm{ng} / \mathrm{mL})$ & T/DHT & Mut1 & Mut2 \\
\hline $1^{\mathrm{c}}$ & 0.06 & 3220 & 50 & -4.6 & 4 & 3.0 & 2.8 & 28 & p.G183S & p.G183S \\
$2^{\mathrm{c}}$ & 18.2 & 2900 & 48 & -4.2 & 3 & 2.5 & 9.0 & 45 & c.418delT & c.418delT \\
$3^{\mathrm{c}}$ & 14.6 & 2800 & 47 & -4.1 & 3 & 2.0 & 2.8 & 28 & p.R246W & p.R246W \\
4 & 5.4 & 2700 & 48 & -4.1 & 2 & 9.0 & 2.2 & 73 & c.278delG & c.278delG \\
$5^{* 1}$ & 3.0 & 2810 & 47 & -4.0 & 3 & 1.0 & 1.8 & 60 & p.Q126R & p.G158R \\
$6^{* 1}$ & 0.05 & 3500 & 50 & -4.0 & 3 & 3.0 & 2.2 & 44 & p.Q126R & p.G158R \\
$7^{\text {c,r }}$ & 16.7 & 2600 & 47 & -4.2 & 3 & 2.5 & 4.9 & 82 & p.G196S & p.G196S \\
$8^{* 2 c, r}$ & 17.3 & 2900 & 49 & -3.9 & 3 & 5.5 & 13.6 & 68 & p.Q126R & p.Q126R \\
$9^{* 2 c, r}$ & 11.0 & 2600 & 48 & -3.1 & 3 & 4.0 & 1.9 & 63 & p.Q126R & p.Q126R \\
\hline
\end{tabular}

Age1: age at first evaluation, T: total testosterone, Mut1: mutation 1, Mut2: mutation 2, +: present, -: absent, ${ }^{*}$ : related, c: presence of consanguinity, r: presence of familial recurrence, Genital ${ }^{1}$ : external genitalia according to Sinnecker et al. [9], Genital ${ }^{2}$ : external genitalia according to Ahmed et al. [10].

TABLE 2: Data from 10 patients (5 families) of PAIS.

\begin{tabular}{lccccccccc}
\hline Case & Age1 (yr) & Birth weight $(\mathrm{g})$ & Birth length $(\mathrm{cm})$ & Penile $(\mathrm{z})$ & Genital $^{1}$ & Genital $^{2}$ & T (ng/mL) & T/DHT & Mutation \\
\hline $1^{* 1 \mathrm{c}}$ & 28.8 & 2900 & 48 & -8.7 & 4 & 1.0 & 10.0 & 33 & p.L830F \\
$2^{* 1 \mathrm{c}}$ & 18.8 & 3330 & 48 & -8.4 & 4 & 2.0 & 15.0 & 50 & p.L830F \\
$3^{* 1 \mathrm{c}}$ & 3.0 & 2800 & 47 & -6.2 & 4 & 2.0 & 3.2 & 32 & p.L830F \\
$4^{* 1 \mathrm{c}}$ & 1.6 & 2650 & 46 & -5.2 & 4 & 2.0 & 1.8 & 60 & p.L830F \\
$5^{* 1 \mathrm{c}}$ & 0.2 & 3180 & 50 & -6.2 & 4 & 5.5 & 2.0 & 67 & p.L830F \\
$6^{* 2}$ & 0.8 & 2630 & 46 & -2.7 & 2 & 5.5 & 1.9 & 63 & p.A596T \\
$7^{* 2}$ & 0.2 & 2900 & 46 & -7.5 & 2 & 2.0 & 1.7 & 34 & p.A596T \\
8 & 1.3 & 3950 & 49 & -3.1 & 2 & 6.0 & 2.9 & 72 & p.A896V \\
9 & 19.2 & 3400 & 51 & -7.5 & 3 & 1.0 & 9.6 & 46 & p.R855H \\
$10^{c}$ & 6.1 & 3150 & 49 & -4.1 & 3 & 3.0 & 2.3 & 57 & p.M742V \\
\hline
\end{tabular}

Age1: age at first evaluation, T: total testosterone, + : present, - : absent, ${ }^{*}$ : related, c: presence of consanguinity, r: presence of familial recurrence, Genital ${ }^{1}$ : external genitalia according to Sinnecker et al. [9], Genital2 ${ }^{2}$ external genitalia according to Ahmed et al. [10].

(Fisher $=1.00)$. However, these classifications showed high negative correlation $(r=-0.675, P=0.0001)$.

Table 5 shows range, mean and standard deviation of age at first evaluation, weight and height at birth, penile length (in $\mathrm{z}$ score), levels of $\mathrm{T}, \Delta 4$-androstenedione, and $\mathrm{T} / \Delta 4$ and $\mathrm{T} / \mathrm{DHT}$ ratios in the three groups. The levels of $\mathrm{LH}$ and FSH were not compared because only a few patients were in pubertal age in each group of diagnosis ( $5 \alpha$-reductase type 2 deficiency: 4 patients, PAIS: 1 patient, and undetermined: 2 patients). The age at first evaluation was significantly lower in idiopathic cases $(P=0.02)$. Weight $(P=0.002)$ and length $(P=0.02)$ at birth and $\mathrm{T} / \mathrm{DHT}$ ratio $(P=0.0001)$ were significantly lower in undetermined cases, and penile length was significantly higher in this group $(P=0.0001)$. The $\mathrm{T}$ $(P=0.07)$ and $\Delta 4$-androstendione $(P=0.12)$ levels and T/ $\Delta 4$ ratio $(P=0.32)$ did not differ among the three groups. All patients showed normal $\Delta 4$-androstendione levels for age and pubertal stage and $\mathrm{T} / \Delta 4$ ratio above 0.8 .

\section{Discussion}

Clinical and laboratorial investigation must include careful and precise anatomical and hormonal studies (both basal and after stimulation) prior to gender assignment in 46,XY patients with undermasculinization (46,XY DSD), which can be difficult in most cases $[1,8,12]$. The phenotypes of
46 ,XY DSD due to $5 \alpha$-reductase type 2 deficiency, PAIS, and disorders in testosterone synthesis may be indistinguishable in newborns $[1-6,8,12]$. The differential diagnosis of PAIS and $5 \alpha$-reductase type 2 deficiency should be established as soon as possible because individuals with PAIS are usually recommended to be raised as females, whereas those with $5 \alpha$-reductase type 2 deficiency as males, when the diagnosis is made early in childhood [1, 6, 8, 12-14].

A correct and early diagnosis is very important because as a result of pre- and/or postnatal brain exposure to androgens, almost $70 \%$ of individuals with $5 \alpha$-reductase type 2 deficiency and 46,XY karyotype raised as girls develop a male gender identity and change the gender behavior in adolescence or early adulthood [2, 4, 15-18]. The degree of external genital masculinization at birth does not seem to be related to gender role changes [18].

At puberty, the differential diagnosis of PAIS and $5 \alpha$ reductase type 2 deficiency can be easier due to the presence of gynecomastia, little genital virilization, and body hair in patients with PAIS, whereas in patients with $5 \alpha$-reductase type 2 deficiency, there is genital virilization, although not always with adequate penile growth, absence of gynecomastia, and absent or hypoplastic prostate [2-5]. Also at puberty, serum levels of $\mathrm{LH}$ and $\mathrm{T}$ are abnormally elevated in patients with PAIS [10]. However, in prepubertal patients with PAIS, serum concentrations of T and LH are generally normal and 
TABLe 3: Data from 39 patients without molecular defects in SRD5A2 and AR genes.

\begin{tabular}{|c|c|c|c|c|c|c|c|c|}
\hline Case & Age1 & Birth weight (g) & Birth length $(\mathrm{cm})$ & Penile $(\mathrm{z})$ & Genital $^{1}$ & Genital $^{2}$ & $\mathrm{~T}(\mathrm{ng} / \mathrm{mL})$ & T/DHT \\
\hline 1 & 0.6 & 2800 & 47 & -4.0 & 3 & 5.5 & 3.7 & 18 \\
\hline $2^{\mathrm{r}}$ & 0.08 & 2650 & 46 & -2.7 & 2 & 6.0 & 3.5 & 12 \\
\hline 3 & 0.04 & 2740 & 47 & -4.0 & 2 & 6.0 & 1.9 & 95 \\
\hline 4 & 0.4 & 2410 & 46 & -2.7 & 2 & 5.0 & 1.7 & 8 \\
\hline 5 & 2.8 & 2700 & 48 & -1.2 & 2 & 10.0 & 1.7 & 8 \\
\hline $6^{\mathrm{r}}$ & 4.1 & 2800 & 47 & -1.1 & 2 & 10.0 & 2.1 & 7 \\
\hline 7 & 0.6 & 1650 & 41 & -3.4 & 2 & 6.5 & 2.1 & 10 \\
\hline 8 & 0.8 & 2580 & 46 & -3.0 & 2 & 8.0 & 2.7 & 13 \\
\hline 9 & 13.8 & 2900 & 47 & -6.5 & 3 & 5.0 & 1.7 & 1 \\
\hline $10^{\mathrm{r}}$ & 20.7 & 2700 & 46 & -5.6 & 2 & 6.0 & 16.0 & 5 \\
\hline 11 & 0.8 & 3000 & 47 & -3.4 & 3 & 6.0 & 1.5 & 3 \\
\hline 12 & 2.4 & 2500 & 49 & -3.1 & 3 & 1.0 & 1.9 & 4 \\
\hline $13^{\mathrm{r}}$ & 2.3 & 2010 & 44 & -3.7 & 2 & 5.0 & 1.8 & 6 \\
\hline $14^{\mathrm{r}}$ & 0.8 & 2900 & 47 & -3.0 & 2 & 6.0 & 3.4 & 11 \\
\hline 15 & 8.1 & 2800 & 48 & -2.0 & 2 & 10.0 & 1.8 & 30 \\
\hline $16^{\mathrm{r}}$ & 0.3 & 2650 & 47 & -2.7 & 2 & 5.5 & 3.6 & 18 \\
\hline 17 & 10.2 & 2110 & 43 & -3.1 & 2 & 8.0 & 1.8 & 18 \\
\hline 18 & 3.8 & 1430 & 39 & -4.0 & 2 & 5.5 & 2.0 & 22 \\
\hline $19^{r}$ & 0.5 & 2500 & 45 & -2.7 & 2 & 6.0 & 1.9 & 9 \\
\hline 20 & 0.04 & 2810 & 46 & -2.1 & 3 & 6.0 & 2.4 & 6 \\
\hline 21 & 0.1 & 2160 & 43 & -2.7 & 2 & 6.0 & 2.3 & 8 \\
\hline 22 & 0.2 & 2600 & 47 & -3.4 & 2 & 5.0 & 3.4 & 8 \\
\hline $23^{r}$ & 0.1 & 3000 & 48 & -4.2 & 2 & 5.0 & 2.0 & 10 \\
\hline $24^{\mathrm{r}}$ & 0.5 & 2700 & 48 & -2.4 & 2 & 9.0 & 6.6 & 17 \\
\hline 25 & 0.07 & 1740 & 42 & -3.1 & 2 & 5.0 & 1.8 & 9 \\
\hline $26^{c}$ & 0.4 & 1700 & 41 & -2.1 & 2 & 9.0 & 2.7 & 9 \\
\hline 27 & 1.9 & 2330 & 42 & -2.9 & 2 & 6.0 & 3.4 & 17 \\
\hline 28 & 0.02 & 2900 & 49 & -2.7 & 2 & 6.0 & 1.8 & 9 \\
\hline 29 & 0.2 & 1540 & 40 & -4.5 & 2 & 6.0 & 1.7 & 8 \\
\hline 30 & 0.06 & 2190 & 42 & -3.4 & 3 & 3.0 & 2.6 & 5 \\
\hline 31 & 0.7 & 1430 & 40 & -3.4 & 2 & 6.0 & 1.6 & 8 \\
\hline 32 & 0.2 & 2250 & 43 & -2.4 & 3 & 5.5 & 1.6 & 55 \\
\hline $33^{r}$ & 0.3 & 2990 & 49 & -2.4 & 2 & 6.0 & 1.6 & 16 \\
\hline 34 & 10.9 & 2800 & 47 & -6.6 & 3 & 1.0 & 1.7 & 8 \\
\hline 35 & 2.6 & 2700 & 49 & -3.1 & 2 & 6.0 & 4.0 & 13 \\
\hline 36 & 0.1 & 2800 & 50 & -2.1 & 2 & 8.5 & 1.9 & 18 \\
\hline $37^{r}$ & 3.7 & 2450 & 49 & -2.7 & 2 & 4.0 & 2.5 & 12 \\
\hline $38^{\mathrm{c}, \mathrm{r}}$ & 0.02 & 2900 & 48 & -2.7 & 3 & 6.0 & 2.2 & 4 \\
\hline $39^{r}$ & 2.7 & 3400 & 51 & -5.9 & 2 & 1.0 & 1.9 & 12 \\
\hline
\end{tabular}

Agel: age at first evaluation, +: present, - : absent, c: presence of consanguinity, r: presence of familial recurrence, T: total testosterone, Genital ${ }^{1}$ : external genitalia according to Sinnecker et al. [9], Genital2 ${ }^{2}$ : external genitalia according to Ahmed et al. [10].

do not help to establish the diagnoses [13]. In addition, T/DHT is usually elevated in prepubertal patients with $5 \alpha$ reductase type 2 deficiency [4]. Surprisingly, in this sample, the T/DHT ratio did not allow differentiation between patients with PAIS and $5 \alpha$-reductase type 2 deficiency, but it was important to differentiate these two groups from undetermined cases. Probably, this result was due to the sensitivity of laboratory methods. Unfortunately, we could not confirmed these results using more specific methods like liquid chromatography linked with tanden mass spectrometry (LC-MS/MS) or immunoassays after organic solvent extraction [19]. $\Delta 4$-androstenedione and $T / \Delta 4$ ratios were normal in all patients evaluated. According to George et al. [20], the diagnosis of $17 \beta$-hydroxysteroid dehydrogenase III deficiency in infants younger than 6 months can be excluded with a basal $\mathrm{T} / \Delta 4$ ratio above 0.8 , with a sensitivity of $100 \%$ and in prepubertal children with the same value of $T / \Delta 4$ ratio after hCG stimulation test, with a sensitivity of $90 \%$.

In the present study, among 51 families evaluated, 7 $(13.7 \%)$ showed homozygous or compound heterozygous mutations in SRD5A2 gene, confirming the diagnosis of $5 \alpha$ reductase type 2 deficiency, 5 (9.8\%) showed hemizygous 
TABle 4: Data from 7 families with $5 \alpha$-reductase type 2 deficiency, 5 families with PAIS, and 39 isolated undetermined cases.

\begin{tabular}{|c|c|c|c|c|c|}
\hline & & $5 \alpha$-reductase type 2 deficiency & PAIS & Undetermined & $P$ value* \\
\hline \multirow{2}{*}{ Parental consanguinity } & + & 5 & 2 & 2 & \multirow{2}{*}{$P=0.00005$} \\
\hline & - & 2 & 3 & 37 & \\
\hline \multirow{3}{*}{ Familial recurrence } & + & 3 & 5 & 13 & \multirow{3}{*}{$P=0.02$} \\
\hline & - & 4 & 0 & 26 & \\
\hline & 2 & 1 & 3 & 29 & \\
\hline \multirow[t]{2}{*}{ Ambiguous genitalia Sinnecker et al. [9] } & 3 & 7 & 2 & 10 & \multirow[t]{2}{*}{$P=0.0004$} \\
\hline & 4 & 1 & 5 & 0 & \\
\hline \multirow{2}{*}{ Ambiguous genitalia Ahmed et al. [10] } & $<3.5$ & 6 & 7 & 4 & \multirow{2}{*}{$P=0.00003$} \\
\hline & $\geq 3.5$ & 3 & 3 & 35 & \\
\hline
\end{tabular}

${ }^{*}$ Chi-square test.

TABle 5: Data from 9 patients with $5 \alpha$-reductase type 2 deficiency, 10 patients with PAIS, and 39 isolated undetermined cases.

\begin{tabular}{|c|c|c|c|c|}
\hline & $5 \alpha$-reductase type 2 deficiency & PAIS & Undetermined & $P$ value* \\
\hline Age at first consultation (yr) & $9.6 \pm 7.5(0.05-18.2)$ & $8.0 \pm 10.0(0.2-28.8)$ & $2.5 \pm 4.5(0,02-20,7)$ & $P=0.02$ \\
\hline Birth weight (g) & $2890 \pm 290(2600-3500)$ & $3100 \pm 400(2630-3950)$ & $2470 \pm 460(1700-3000)$ & $P=0.002$ \\
\hline Birth length $(\mathrm{cm})$ & $48 \pm 1(47-50)$ & $48 \pm 2(46-51)$ & $46 \pm 3(39-50)$ & $P=0.02$ \\
\hline Penile length (z) & $-4.0 \pm 0.4(-4.6--3.1)$ & $-6.0 \pm 2.1(-8.7--2.7)$ & $-3.2 \pm 1.2(-6.6--1.1)$ & $P=0.0001$ \\
\hline $\mathrm{T}(\mathrm{ng} / \mathrm{mL})$ & $4.6 \pm 4.1(1.8-13.6)$ & $4.5 \pm 4.4(1.7-15.0)$ & $2.6 \pm 1.4(1.5-9.1)$ & $P=0.07$ \\
\hline$\Delta 4(\mathrm{ng} / \mathrm{mL})$ & $1.4 \pm 0.4(0.8-1.9)$ & $1.1 \pm 0.4(0.7-1.9)$ & $1.2 \pm 0.3(0.7-1.7)$ & $P=0.12$ \\
\hline $\mathrm{T} / \Delta 4$ ratio & $3.0 \pm 1.9(1.5-7.2)$ & $3.6 \pm 1.9(2.1-7.9)$ & $2.7 \pm 0.9(1.8-7.0)$ & $P=0.32$ \\
\hline T/DHT ratio & $54 \pm 19(28-82)$ & $51 \pm 15(32-72)$ & $14 \pm 16(1-95)$ & $P=0.0001$ \\
\hline
\end{tabular}

${ }^{*}$ Kruskal-Wallis test.

mutation in $A R$ gene, confirming the diagnosis of PAIS, and the remaining $39(76.4 \%)$ cases showed normal molecular analysis of SRD5A2 and AR genes. Based on the literature available, we expected more cases of PAIS $[21,22]$ and up to $30-40 \%$ of undetermined cases $[6,8]$. In addition, probably more patients would be diagnosed with PAIS and mutations in the $A R$ gene if the $A R$ promoter region and $3^{\prime} U T R$ were evaluated, and we must also remember that the $A R$ gene in target tissues from patients with hypospadias is more methylated than in control children, resulting in a decreased expression of the $A R$. This epigenetic alteration of the $A R$ gene might be involved in the pathogenesis of hypospadias [23].

As expected, the frequency of parental consanguinity was higher in patients with $5 \alpha$-reductase type 2 deficiency, which is a male-limited autosomal recessive disorder (OMIM 264600), whereas the familial recurrence was higher in PAIS, an X-linked disorder (OMIM 300068).

Weight and length at birth were lower in undetermined cases, suggesting that metabolic and endocrine disorders as fetal malnutrition could play a role in poor external genitalia development. Morel et al. showed that, in comparison with PAIS, undetermined 46,XY DSD was characterized by a high incidence of prematurity and/or intrauterine growth retardation (30\%) [8]. In the present study, 12/39 (30.7\%) undetermined cases had birth weight lower than 2,500 g. De Andrade Machado Neto et al. [24] showed an association between prenatal growth retardation and 46,XY DSD which may be due to genetic factors not clarified yet or to environmental factors which act early in gestation. Scaramuzzo et al. recently demonstrated that in the first days of life, small-for-gestational-age male pre-term newborns have reduced testosterone levels compared with adequatefor-gestational-age preterm newborns, independently from the presence of abnormalities of the external genitalia [25]. Low testosterone levels were not observed in our patients with low birth weight and length probably due to the gestational age, as all patients included in this study were born at term. Nutrition is the major intrauterine environmental factor that alters expression of the fetal genome and may have lifelong consequences (fetal programming). Alterations in fetal nutrition and endocrine status may result in developmental adaptations that permanently change the structure, physiology, and metabolism of the offspring, predisposing individuals to metabolic, endocrinological, and cardiovascular diseases in adult life [26, 27]. Furthermore, it may be that sexual plasticity during development explains the vulnerability of organisms to androgen influences, such as environmental oestrogens or endocrine disruptors [2831 . The severity of ambiguous genitalia was higher in $5 \alpha$ reductase type 2 deficiency in comparison with PAIS and undetermined cases. The $5 \alpha$-reductase type 2 deficiency has frequently a classical syndrome of pseudovaginal perineoscrotal hypospadias, characterized by a predominantly female phenotype at birth and significant virilization at puberty [9]. Recent reports have shown the clinical spectrum to be heterogeneous, ranging from the classic phenotype to males with hypospadias and even micropenis [32]. 
The age at first evaluation was lower in undetermined cases, and this data can be associated with severity of ambiguous genitalia: $5 \alpha$-reductase type 2 deficiency and PAIS groups have more cases with Sinnecker et al. [9], classification grades 3 and 4, and Ahmed et al. [10] score below 3.5 than undetermined cases and may be more frequently underdiagnosed. The penile length, that was higher in undetermined cases, reinforces this hypothesis.

In conclusion, birth weight and length, parental consanguinity, familial recurrence, severity of ambiguous genitalia, penile length, and T/DHT ratio may help the investigation of 46 , XY patients with ambiguous genitalia and normal testosterone synthesis.

\section{Disclosure}

The authors have nothing to disclose.

\section{Author's Contribution}

N. N. Veiga-Junior, P. A. R. Medaets, R. J. Petroli, and F. L. Calais made an equal contribution to this paper.

\section{Acknowledgments}

The authors thank the National Council for Scientific and Technological Development $(\mathrm{CNPq})$ for providing research fellowship (to MPM, ATM-G, GG-J) and undergraduate research internship (to NNV-J, PARM), the Coordination for Higher Level Graduates Improvement (CAPES) for doctoral research scholarship (to RJP, FLC), and Sao Paulo Research Foundation (FAPESP) for research financial support (Grant no. 2009/08320-9 to M. P. Mello).

\section{References}

[1] P. A. Lee, C. P. Houk, S. F. Ahmed et al., "Consensus statement on management of intersex disorders," Pediatrics, vol. 118, no. 2, pp. e488-e500, 2006.

[2] J. Imperato-McGinley and Y. S. Zhu, "Androgens and male physiology the syndrome of $5 \alpha$-reductase- 2 deficiency," Molecular and Cellular Endocrinology, vol. 198, no. 1-2, pp. 51-59, 2002.

[3] I. A. Hughes and A. Deeb, "Androgen resistance," Best Practice and Research, vol. 20, no. 4, pp. 577-598, 2006.

[4] C. K. Cheon, "Practical approach to steroid 5alpha-reductase type 2 deficiency," European Journal of Pediatrics, vol. 170, no. 1 , pp. 1-8, 2010.

[5] A. Galani, S. Kitsiou-Tzeli, C. Sofokleous, E. Kanavakis, and A. Kalpini-Mavrou, "Androgen insensitivity syndrome: clinical features and molecular defects," Hormones, vol. 7, no. 3, pp. 217-229, 2008.

[6] B. B. Mendonça, S. Domenice, I. J. P. Arnhold, and E. M. F. Costa, "46,XY disorders of sex development (DSD)," Clinical Endocrinology, vol. 70, no. 2, pp. 173-187, 2009.

[7] N. Hussain, A. Chaghtai, C. D. Anthony Herndon, V. C. Herson, T. S. Rosenkrantz, and P. H. McKenna, "Hypospadias and early gestation growth restriction in infants," Pediatrics, vol. 109, no. 3, pp. 473-478, 2002.

[8] Y. Morel, R. Rey, C. Teinturier et al., "Aetiological diagnosis of male sex ambiguity: a collaborative study," European Journal of Pediatrics, vol. 161, no. 1, pp. 49-59, 2002.
[9] G. H. G. Sinnecker, O. Hiort, L. Dibbelt et al., "Phenotypic classification of male pseudohermaphroditism due to steroid $5 \alpha$-reductase 2 deficiency," American Journal of Medical Genetics, vol. 63, no. 1, pp. 223-230, 1996.

[10] S. F. Ahmed, O. Khwaja, and I. A. Hughes, "The role of a clinical score in the assessment of ambiguous genitalia," BJU International, vol. 85, no. 1, pp. 120-124, 2000.

[11] P. N. Gabrich, J. S. P. Vasconcelos, R. Damião, and E. A. Da Silva, "Penile anthropometry in Brazilian children and adolescents," Jornal de Pediatria, vol. 83, no. 5, pp. 441-446, 2007.

[12] P. A. Tomasi, "Sex determination, differentiation, and identity," The New England Journal of Medicine, vol. 350, no. 21, pp. 2204-2204, 2004.

[13] J. H. Choi, G. H. Kim, E. J. Seo, K. S. Kim, S. H. Kim, and H. W. Yoo, "Molecular analysis of the AR and SRD5A2 genes in patients with 46,XY disorders of sex development," Journal of Pediatric Endocrinology and Metabolism, vol. 21, no. 6, pp. 545-553, 2008.

[14] A. B. Wisniewski and T. Mazur, "46,XY DSD with female or ambiguous external genitalia at birth due to androgen insensitivity syndrome, 5alpha-reductase-2 deficiency, or 17beta-hydroxysteroid dehydrogenase deficiency: a review of quality of life outcomes," International Journal of Pediatric Endocrinology, vol. 2009, Article ID 567430, 7 pages, 2009.

[15] E. P. Praveen, A. K. Desai, M. L. Khurana et al., "Gender identity of children and young adults with $5 \alpha$-reductase deficiency," Journal of Pediatric Endocrinology and Metabolism, vol. 21, no. 2, pp. 173-179, 2008.

[16] L. Maimoun, P. Philibert, B. Cammas et al., "Phenotypical, biological, and molecular heterogeneity of $5 \alpha$-reductase deficiency: an extensive international experience of 55 patients," The Journal of Clinical Endocrinology \& Metabolism, vol. 96, no. 2, pp. 296-307, 2011.

[17] P. T. Cohen-Kettenis, "Gender change in 46,XY persons with 5alpha-reductase-2 deficiency and 17beta-oxysteroid dehydrogenase-3 deficiency," Archives of Sexual Behavior, vol. 34, pp. 399-410, 2005.

[18] J. Imperato-McGinley, R. E. Peterson, T. Gautier, and E. Sturla, "Androgens and the evolution of male-gender identity among male pseudohermaphrodites with $5 \alpha$-reductase deficiency," The New England Journal of Medicine, vol. 300, no. 22, pp. 1233-1237, 1979.

[19] J. Nakamoto and J. S. Fuqua, "Laboratory assays in pediatric endocrinology: common aspects," Pediatric Endocrinology Reviews, vol. 5, supplement 1, pp. 539-554, 2007.

[20] M. M. George, M. I. New, S. Ten, C. Sultan, and A. Bhangoo, "The clinical and molecular heterogeneity of $17 \beta$ HSD-3 enzyme deficiency," Hormone Research in Paediatrics, vol. 74, no. 4, pp. 229-240, 2010.

[21] S. F. Ahmed, A. Cheng, L. Dovey et al., "Phenotypic features, androgen receptor binding, and mutational analysis in 278 clinical cases reported as androgen insensitivity syndrome," The Journal of Clinical Endocrinology \& Metabolism, vol. 85, no. 2, pp. 658-665, 2000.

[22] A. L. M. Boehmer, H. Brüggenwirth, C. van Assendelft et al., "Genotype Versus phenotype in families with androgen insensitivity syndrome," The Journal of Clinical Endocrinology \& Metabolism, vol. 86, no. 9, pp. 4151-4160, 2001.

[23] A. Vottero, R. Minari, I. Viani et al., "Evidence for epigenetic abnormalities of the androgen receptor gene in foreskin from children with hypospadias," The Journal of Clinical Endocrinology \& Metabolism, vol. 96, no. 12, pp. E1953-E1962, 2011. 
[24] F. De Andrade Machado Neto, A. Moreno Morcillo, A. Trevas Maciel-Guerra, and G. Guerra-Junior, "Idiopathic male pseudohermaphroditism is associated with prenatal growth retardation," European Journal of Pediatrics, vol. 164, no. 5, pp. 287291, 2005.

[25] R. T. Scaramuzzo, A. Boldrini, S. Bertelloni, D. Parrini, L. Serino, and P. Ghirri, "Low testosterone levels in pre-term newborns born small for gestational age," Journal of Endocrinological Investigation, vol. 33, no. 4, pp. 215-217, 2010.

[26] S. M. Rhind, M. T. Rae, and A. Nigel Brooks, "Effects of nutrition and environmental factors on the fetal programming of the reproductive axis," Reproduction, vol. 122, no. 2, pp. 205214, 2001.

[27] G. Wu, F. W. Bazer, T. A. Cudd, C. J. Meininger, and T. E. Spencer, "Maternal nutrition and fetal development," Journal of Nutrition, vol. 134, no. 9, pp. 2169-2172, 2004.

[28] G. Schoeters, E. Den Hond, W. Dhooge, N. van Larebeke, and M. Leijs, "Endocrine disruptors and abnormalities of pubertal development," Basic and Clinical Pharmacology and Toxicology, vol. 102, no. 2, pp. 168-175, 2008.

[29] S. Özen and S. Darcan, "Effects of environmental endocrine disruptors on pubertal development," JCRPE, vol. 3, no. 1, pp. $1-6,2011$.

[30] T. M. Edwards, B. C. Moore, L. J. Guillette Jr., N. Olea, J. McLachlan, and D. Page, "Reproductive dysgenesis in wildlife: a comparative view," International Journal of Andrology, vol. 29, no. 1, pp. 109-121, 2006.

[31] F. Paris, C. Jeandel, N. Servant, and C. Sultan, "Increased serum estrogenic bioactivity in three male newborns with ambiguous genitalia: a potential consequence of prenatal exposure to environmental endocrine disruptors," Environmental Research, vol. 100, no. 1, pp. 39-43, 2006.

[32] A. Nicoletti, L. Baldazzi, A. Balsamo et al., "SRD5A2 gene analysis in an Italian population of under-masculinized 46,XY subjects," Clinical Endocrinology, vol. 63, no. 4, pp. 375-380, 2005. 


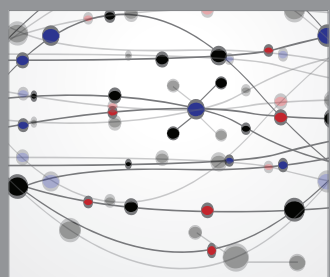

The Scientific World Journal
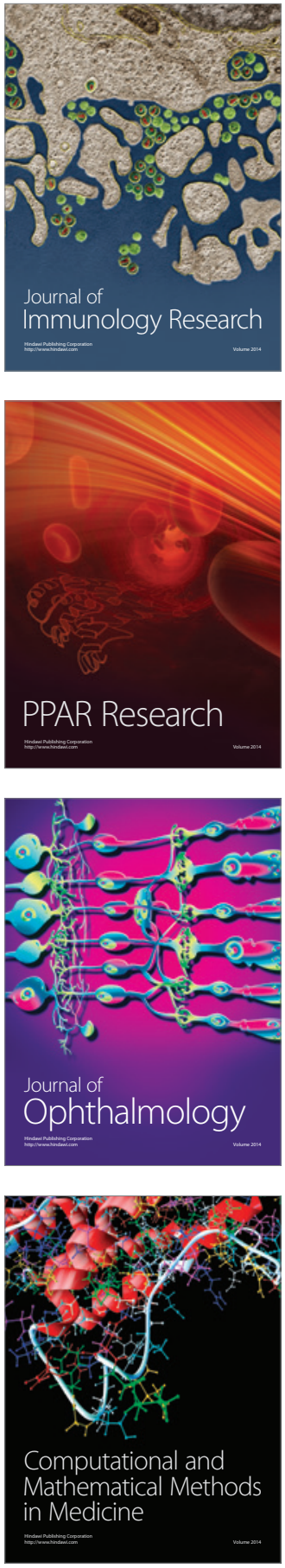

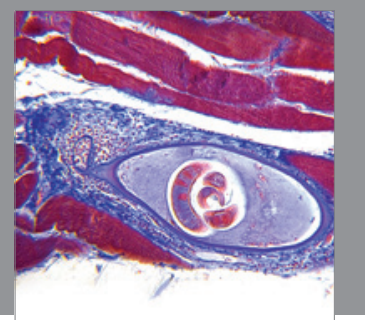

Gastroenterology

Research and Practice
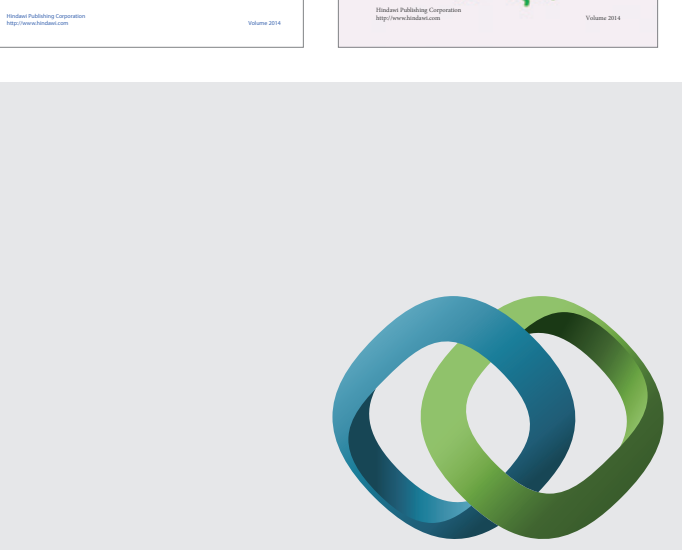

\section{Hindawi}

Submit your manuscripts at

http://www.hindawi.com
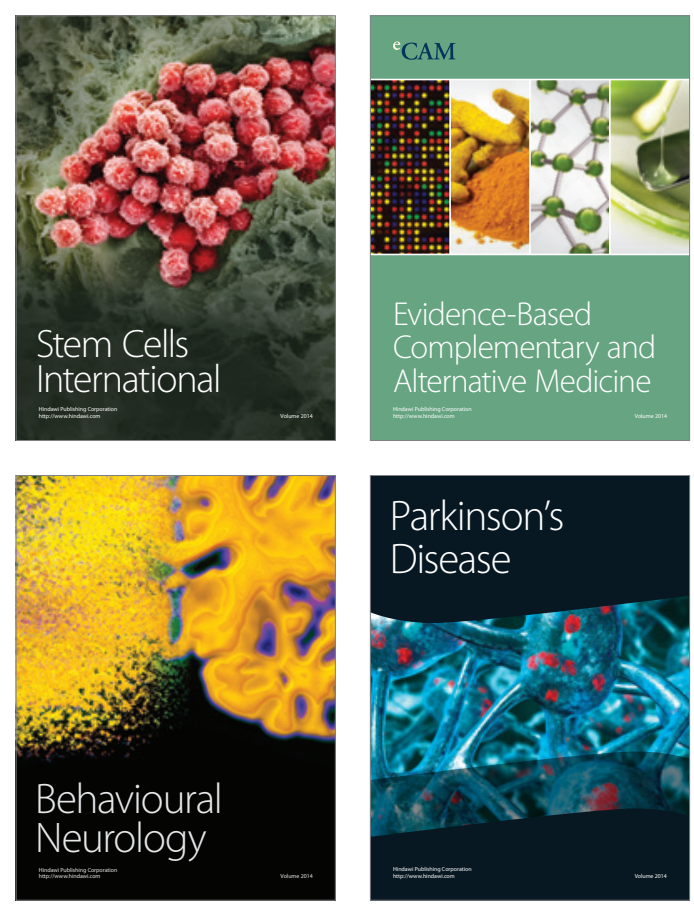

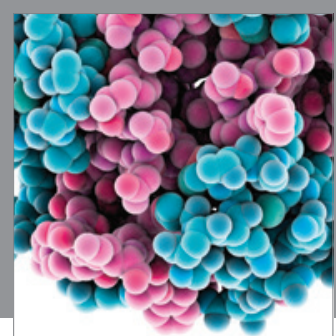

Journal of
Diabetes Research

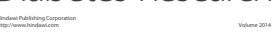

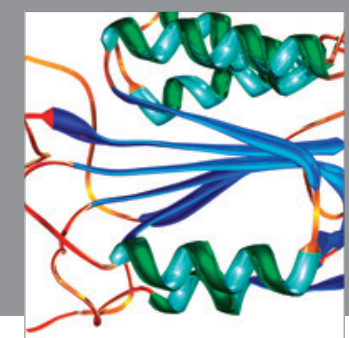

Disease Markers
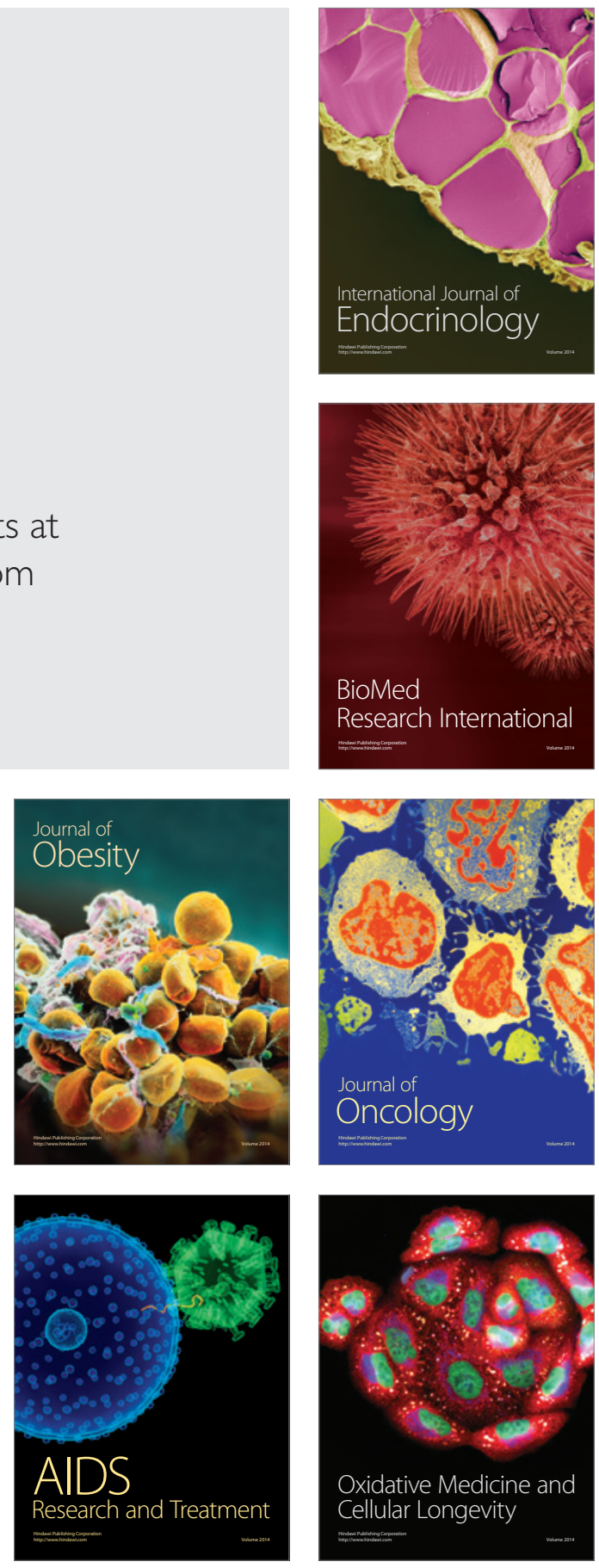